\title{
Bowel Ischemia: A Rare Complication of Thiopental Treatment for Status Epilepticus
}

\author{
Carlo Cereda $\cdot$ Mette M. Berger $\cdot$ Andrea O. Rossetti
}

Published online: 25 November 2008

(C) Humana Press Inc. 2008

\begin{abstract}
Background Refractory status epilepticus (RSE) treatment is usually performed with comainduction using an appropriate general anesthetic. Most frequent complications are represented by hypotension and infection. Other side-effects may however be encountered.

Observations We describe two patients suffering from acute bowel ischemia after thiopental (THP) treatment for RSE. A 73-year-old man with a complex-patial RSE following an acute stroke received THP $(303 \mathrm{mg} / \mathrm{kg}$ over $48 \mathrm{~h}) ; 36 \mathrm{~h}$ after THP discontinuation, he presented abdominal tenderness and lactate elevation. Necrosis of the terminal ileum and colon was seen during surgical exploration; he deceased shortly thereafter. A 21 year-old woman had a cryptogenic de novo generalized-convulsive RSE resistant to 5 attempts of EEG burst-suppression. During the 6th attempt, after THP $(840 \mathrm{mg} / \mathrm{kg}$ over $150 \mathrm{~h})$ together with mild hypothermia, she developed an ileus with elevated serum lactate; caecum necrosis was observed during surgery. Hypernatremia, acidosis and hyperlactatemia heralded this complication in both patients.

Conclusion In these two patients, mechanical vascular ischemia may have resulted from drug-induced paralytic
\end{abstract}

This paper was presented in part at the 18th Meeting of the European Neurological Society, Nice (F), 7-11 June 2008.

C. Cereda $\cdot$ A. O. Rossetti $(\bowtie)$

Department of Neurology, Centre Hospitalier Universitaire

Vaudois and University of Lausanne, CHUV BH-07,

Lausanne 1011, Switzerland

e-mail: andrea.rossetti@chuv.ch

M. M. Berger

Department of Adult Intensive Care Medicine, Centre

Hospitalier Universitaire Vaudois and University of Lausanne,

Lausanne, Switzerland ileus. To our knowledge, this is the first report describing this potential fatal side effect in adults with RSE.

Keywords Thiopental · Epilepsy ·

Refractory status epilepticus - Bowel ischemia

Status epilepticus (SE) has a yearly incidence of 10 to $41 /$ 100,000 and is the second most common life-threatening neurological emergency after stroke [1]. Refractory status epilepticus (RSE) is considered when administration of benzodiazepines and second line AEDs (e.g. phenytoin, valproic acid, or phenobarbital) fail to control SE [2]. Treatment of RSE aims at EEG background suppression with an appropriate anesthetic agent, such as midazolam, propofol, or barbiturates (thiopental (THP) in Europe; or pentobarbithal in North America) [3, 4]. Most cited complications related to these agents are represented by arterial hypotension, "infusion syndrome", or infections $[3,5,6]$. We report here on two patients with RSE, who underwent THP treatment for RSE and suffered from acute bowel ischemia, which appears to represent a rare but potentially fatal complication.

\section{Patient 1}

A 73-year-old man presented an acute-onset language disturbance and was admitted to our emergency department. His past medical history was characterized by chronic hepatitis C leading to cirrhosis (Child B), as well as a valvular cardiopathy treated with diuretics. On arrival, he displayed fluent aphasia with a severe understanding deficit. A brain computer tomography with perfusion images 
Table 1 Demographical and clinical data of the two patients

$A E D$ antiepileptic drugs, $B S$ burst-suppression; $C L Z$ clonazepam, $L Z P$ lorazepam, $P H T$ phenytoin, $R S E$ refractory status epilepticus, THP thiopental, TPM topiramate, $V P A$ valproate

\begin{tabular}{lll}
\hline Patient & 1 & 2 \\
\hline Gender & $\mathrm{M}$ & $\mathrm{F}$ \\
Age (years) & 73 & 21 \\
Weight $(\mathrm{kg})$ & 65 & 58 \\
RSE type & Complex partial & Secondary generalized \\
RSE etiology & Acute stroke & Cryptogenic \\
Duration of THP administration $(\mathrm{h})$ & 48 & 150 \\
Total THP dose $(\mathrm{mg} / \mathrm{kg})$ & 303 & 840 \\
Highest daily THP dose $(\mathrm{g})$ & 12 & 9 \\
Highest THP infusion rate $(\mathrm{mg} / \mathrm{kg} / \mathrm{h})$ & 15 & 8 \\
Concomitant norepinephrine administration rate $(\mu \mathrm{g} / \mathrm{min})$ & $10-20$ & $10-20$ \\
Sodium maximal level $12 \mathrm{~h}$ before surgery $(\mathrm{mmol} / \mathrm{l})$ & 150 & 152 \\
AED co-medication & LZP, PHT, VPA & CLZ, PHT, TPM \\
Latency BS end-lactate peak $(\mathrm{h})$ & 72 & 0 \\
Lactate peak (norm $<1.5 \mathrm{mmol} / \mathrm{l})$ & 10.5 & 5.6 \\
Lowest arterial pH & 7.36 & 7.22 \\
Final outcome & Dead & Refractory epilepsy \\
\hline
\end{tabular}

showed an acute left parieto-occipital stroke and a chronic left frontal ischemic lesion. Shortly thereafter, he had a generalized tonic clonic seizure; he received $1 \mathrm{mg}$ clonazepam i.v. An EEG showed continuous epileptiform activity in the left temporal area with periodic lateralized epileptiform discharges (PLEDs). The patient subsequently developed repetitive complex-partial seizures (right hemibody clonic convulsions with right sided nystagmus and consciousness impairment). Despite treatment with intravenous lorazepam, phenytoin, and valproate, at therapeutic serum levels, his condition worsened, with progressive consciousness impairment and language disturbances; a persistent epileptic activity was observed on follow-up EEGs. After $72 \mathrm{~h}$, with the diagnosis of complex-partial RSE, he was electively transferred to the intensive care unit, and an EEG burst-suppression pattern was achieved with a THP drip (total dose: $303 \mathrm{mg} / \mathrm{kg}$ over $48 \mathrm{~h}$ ); baseline AED treatment was continued. Thirty-six hours after THP discontinuation and after more than $72 \mathrm{~h}$ of burstsuppression, the still comatose patient had a sudden elevation of lactate levels (peaking at $10.5 \mathrm{mmol} / \mathrm{l}$ ), associated with new-onset peritonismus. Of note, he did not experience significant arterial hypotension (because he was under norepinephrine administration) during THP treatment and thereafter. An emergency surgical exploration showed an extensive, fresh necrosis of the terminal ileum and of the left and right colon until the recto-sigmoid junction. The bioptic material did not show any vascular lesion (thrombotic or inflammatory). Still in the operation room, he developed a septic shock and died $12 \mathrm{~h}$ after the intervention. Data regarding thiopental therapy and pertinent clinical findings are given in Table 1.

\section{Patient 2}

A 21-year-old woman with a complete negative medical history was admitted after a viral upper airways infection to the intensive care unit, because of de novo complex-partial seizures (right facial myoclonus with consciousness alteration) followed by secondary generalized SE. Etiology remained undetermined despite exhaustive investigations: several brain MRI and CSF examinations, as well as extended infectious, immunological, and metabolic disorders screenings were repeatedly negative. Her SE was resistant to an initial treatment of intravenous high-dosage clonazepam, phenytoine, valproate, levetiracetam, and oral topiramate (administered through the nasogastric tube). She also did not respond to five courses of EEG burstsuppression attempts (with propofol (up to $10 \mathrm{mg} / \mathrm{kg} / \mathrm{h}$ ); thiopental $(6-8 \mathrm{mg} / \mathrm{kg} / \mathrm{h})$; ketamine (up to $12 \mathrm{mg} / \mathrm{kg} / \mathrm{h}$ ) combined with midazolam $(0.5 \mathrm{mg} / \mathrm{kg} / \mathrm{h})$; THP $(6-8 \mathrm{mg}$ / $\mathrm{kg} / \mathrm{h})$; propofol $(4-7 \mathrm{mg} / \mathrm{kg} / \mathrm{h})$ combined with midazolam $(0.5-0.8 \mathrm{mg} / \mathrm{kg} / \mathrm{h}))$, targeting burst-suppression for at least $24 \mathrm{~h}$, and up to 7 days, and periodically weaning the anesthetics to observe EEG and clinical evolution. During the sixth attempt, after more than 2 months of ICU treatment, THP was administered together with mild hypothermia $\left(34^{\circ} \mathrm{C}\right)$, which was achieved with an external cooling, and other AED (see Table 1) in order to obtain a transitory complete EEG suppression. Daily THP dosage was reduced stepwise after the first $48 \mathrm{~h}$; she received a total dose of $840 \mathrm{mg} / \mathrm{kg}$ over $150 \mathrm{~h}$. No systemic arterial hypotension was noted (under norepinephrine administration). On the sixth day (after THP discontinuation), she developed an ileus with elevated serum lactate (peaking at 
$5.6 \mathrm{mmol} / \mathrm{l})$; her body temperature at this time was $36.5^{\circ} \mathrm{C}$. The visceral surgeon described a megacolon with focal cecum necrosis, but no sign of vascular or inflammatory changes was noted on histological examination. After a partial right colon resection, the patient recovered following a seventh burst-suppression treatment with propofol coupled with midazolam. At 12 months follow-up, she still has refractory, complex-partial seizures, and a marked neuropsychological impairment. A representation of thiopental therapy and other clinical findings are seen in Table 1.

\section{Discussion}

These two patients developed intestinal ischemia during RSE treatment and after high-dose THP administration; both patients were fed enterally during THP administration and thereafter. While SE etiology in the first subject was related to his acute stroke, the second patient probably had "de novo" SE, which often proves very difficult to treat [7] and is probably related to inflammatory or infectious causes [8].

Ileus represents a relatively rare side effect of highdose barbiturates, occurring in about $10 \%$ of patients according to a recent series [9]. However, to the best of our knowledge, it has only been anecdotally described in the context of RSE treatment in children treated with THP [10], but without complications such as intestinal infarction or death. Of note, adult RSE series do not mention this complication [3,5]. In our center, we treat RSE preferentially with propofol since 10 years (more than 50 cases to date), and so far we did not observe ileus in this setting [11]. Intestinal infarction complicating barbiturates administration has been also rarely reported: a 29 -year-old patient presented a non-occlusive intestinal ischemia after oral phenobarbital overdose. The proposed mechanism was a combination of mild arterial hypotension, hypothermia (rectal temperature, $33.3^{\circ} \mathrm{C}$ ), hypoxemia (due to a presumed respiratory arrest), and hemoconcentration. The absence of co-morbidity and the young age were discussed as the principal factors explaining the full recovery [12].

Reports of intestinal ischemia associated with SE (regardless of the treatment) are also exceptional. A 19year-old woman presented with SE (and cardiac ventricular arrhythmias) after massive ingestion of an antihistaminic compound ( $5 \mathrm{~g}$ of dimenhydrinate) in a suicidal attempt. Despite maximal supportive treatment, she developed bowel ischemia necessitating a colonic resection. After surgery, her condition worsened and following demonstration of minimal cerebral activity, supportive measures were eventually withdrawn [13]. There was no mention of barbiturates administration, and it appears plausible that the ingested drug contributed to her ileus.

In intensive care medicine and anesthesiology, nonocclusive mesenteric ischemia (NOMI) is a relatively common disorder [14], and is encountered in conditions such as exposure to toxic amounts of vasoactive drugs (including ergotamine, digitalis) with an underlying cardiovascular and renal disease in critically ill patients, or during major operations. While our first patient had a well compensated valvular cardiopathy, the second one was previously healthy, and in both administration of norepinephrine was performed to compensate for the known hypotensive effect of THP [3]. The mechanism underlying NOMI is probably multifactorial, including large vessel vasoconstriction, which might be the consequence of the action of various drugs (e.g., sympathomimetics or digitalis), and hypoperfusion of mesenteric arteries (anemia, severe hypoxia, cardiovascular shock, sepsis). NOMI is strongly associated with a dismal prognosis [14].

Although the underlying mechanism in our patients remains unproven, we suggest the etiological role of THP-induced paralytic ileus, possibly complicated by hypothermia in the second subject. Of note, there are very few patients with RSE treated with hypothermia reported in the literature, but ileus does not seem to be very common [15]. Histological examination in our patients failed to show any inflammatory or atherosclerotic change, and no suspicion of abdominal compartment syndrome was mentioned by the surgeons. Table 1 shows that both subjects received a high THP load: the total dose was considerably higher as compared to that normally used for neuroprotection after traumatic brain injury [16]. The latency between the weaning of THP administration and ileus diagnosis may be explained by the very long elimination THP half-life following redistribution into the fat tissue [17]. Furthermore, our two patients shared a distinctive metabolic profile preceding the event, with hypernatremia (probably as a result of sodium THP administration) together with acidosis and hyperlactatemia. Despite lactate elevation, a "thiopental infusion syndrome" seems unlikely, given the absence of other signs of this complication (rhabdomyolysis, myocardial failure) [18]. Regardless of the precise etiology, selective attention to these parameters and clinical abdominal survey appear mandatory in order to detect early this rare but potentially fatal complication.

\section{References}

1. Lowenstein DH. The management of refractory status epilepticus: an update. Epilepsia. 2006;47(Suppl 1):35-40. doi:10.1111/ j.1528-1167.2006.00658.x.

2. Bleck TP. Refractory status epilepticus. Curr Opin Crit Care. 2005;11(2):117-20. doi:10.1097/01.ccx.0000157079.72999.87. 
3. Claassen J, Hirsch LJ, Emerson RG, Mayer SA. Treatment of refractory status epilepticus with pentobarbital, propofol, or midazolam: a systematic review. Epilepsia. 2002;43(2):146-53. doi:10.1046/j.1528-1157.2002.28501.x.

4. Rossetti AO. Which anesthetic drug should be used in the treatment of refractory status epilepticus? Epilepsia. 2007;48(Supp1 8):52-5. doi:10.1111/j.1528-1167.2007.01350.x.

5. Parviainen I, Uusaro A, Kalviainen R, Kaukanen E, Mervaala E, Ruokonen E. High-dose thiopental in the treatment of refractory status epilepticus in intensive care unit. Neurology. 2002;59(8): 1249-51. doi:10.1001/archneur.59.8.1249.

6. Zarovnaya EL, Jobst BC, Harris BT. Propofol-associated fatal myocardial failure and rhabdomyolysis in an adult with status epilepticus. Epilepsia. 2007;48(5):1002-6. doi:10.1111/j.15281167.2007.01042.x.

7. Robakis TK, Hirsch LJ. Literature review, case report, and expert discussion of prolonged refractory status epilepticus. Neurocrit Care. 2006;4(1):35-46. doi:10.1385/NCC:4:1:035.

8. Holtkamp M, Othman J, Buchheim K, Masuhr F, Schielke E, Meierkord H. A "malignant" variant of status epilepticus. Arch Neurol. 2005;62(9):1428-31. doi:10.1001/archneur.62.9.1428.

9. Chin K, Ng S, Kwek T. Thiopentone barbiturate coma: a review of outcomes and complications. Can J Anaesth. 2006;53:26098.

10. Lee WK, Liu KT, Young BW. Very-high-dose phenobarbital for childhood refractory status epilepticus. Pediatr Neurol. 2006;34(1):63-5. doi:10.1016/j.pediatrneurol.2005.06.014.

11. Rossetti AO, Reichhart MD, Schaller MD, Despland PA, Bogousslavsky J. Propofol treatment of refractory status epilepticus: a study of 31 episodes. Epilepsia. 2004;45(7):757-63. doi:10.1111/j.0013-9580.2004.01904.x.

12. Olson KR, Pond SM, Verrier ED, Federle M. Intestinal infarction complicating phenobarbital overdose. Arch Intern Med. 1984; 144(2):407-8. doi:10.1001/archinte.144.2.407.

13. Winn RE, McDonnell KP. Fatality secondary to massive overdose of dimenhydrinate. Ann Emerg Med. 1993;22(9):1481-4. doi:10.1016/S0196-0644(05)82001-3.

14. Kolkman JJ, Mensink PB. Non-occlusive mesenteric ischaemia: a common disorder in gastroenterology and intensive care. Best Pract Res Clin Gastroenterol. 2003;17(3):457-73. doi:10.1016/ S1521-6918(03)00021-0.

15. Corry JJ, Dhar R, Murphy T, Diringer MN. Hypothermia for refractory status epilepticus. Neurocrit Care. 2008;9(2):189-97. doi:10.1007/s12028-008-9092-9.

16. Eisenberg HM, Frankowski RF, Contant CF, Marshall LF, Walker MD. High-dose barbiturate control of elevated intracranial pressure in patients with severe head injury. J Neurosurg. 1988;69(1):15-23.

17. Van Ness PC. Pentobarbital and EEG burst suppression in treatment of status epilepticus refractory to benzodiazepines and phenytoin. Epilepsia. 1990;31(1):61-7. doi:10.1111/j.1528-1157. 1990.tb05361.x.

18. Enting D, Ligtenberg JJ, Aarts LP, Zijstra JG. Total suppression of cerebral activity by thiopental mimicking propofol infusion syndrome: a fatal common pathway? Anesth Analg. 2005;100(6): 1864-5. doi:10.1213/01.ANE.0000156682.59859.F3. 